EDITORIAL

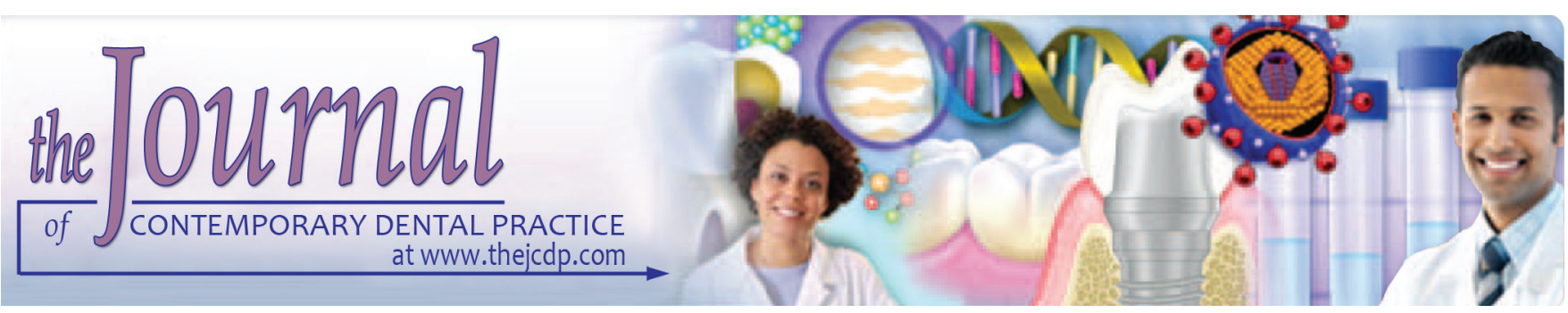

\title{
Three-dimensional Printing in Reconstructive Oral and Maxillofacial Surgery
}

${ }^{1}$ T Srinivasa Prasad, ${ }^{2}$ Govindarajan Sujatha, ${ }^{3}$ Jayanandan Muruganandhan, ${ }^{4}$ Shankargouda Patil, ${ }^{5} \mathrm{~A}$ Thirumal Raj

How to cite this article: PrasadTS, Sujatha G, Muruganandhan J, Patil S, Raj AT. Three-dimensional Printing in Reconstructive Oral and Maxillofacial Surgery. J Contemp Dent Pract 2018;19(1):1-2.

\section{Source of support: Nil}

Conflict of interest: None

Three-dimensional (3D) printing involves the process of constructing a 3D solid object from a digital file. Charles Hull was the first to introduce 3D printer in 1983 by using the technique of stereolithography. ${ }^{1}$ Since the 1990s 3D printing has gained attention in the field of medicine where more precision is required and has largely replaced the traditional technique in prosthetic works. ${ }^{2,3}$

Its initial use was restricted to visual models and tooling molds. The models gave a good approach to surgical techniques and helped the surgeons understand the complex structures before surgery. The models were used as good surgical guides, as learning modules to students, and for conducting various blocks to augment bone defects. ${ }^{4}$ In dental implantology, it established guidelines for insertion of dental implants and prints tailored to bone tissue as well as acts as a scaffold for bone cell enhancement and differentiation. ${ }^{5}$

\footnotetext{
${ }^{1}$ Department of Oral and Maxillofacial Surgery, Meenakshi Ammal Dental College \& Hospital, Meenakshi Academy of Higher Education and Research University, Chennai, Tamil Nadu, India

2,3,5 Department of Oral Pathology and Microbiology, Sri Venkateswara Dental College and Hospital, Chennai, Tamil Nadu, India

${ }^{4}$ Division of Oral Pathology, Department of Maxillofacial Surgery and Diagnostic Sciences, College of Dentistry, Jazan University Jazan, Kingdom of Saudi Arabia

Corresponding Author: A Thirumal Raj, Department of Oral Pathology and Microbiology, Sri Venkateswara Dental College and Hospital, Chennai, Tamil Nadu, India, e-mail: thirumalraj666@gmail.com
}

In dentistry, the current applications of 3D printing come under major categories. Metal frameworks including cast partial dentures and fixed prosthesis are mainly fabricated by selective laser melting. ${ }^{6}$ The most popular and long-standing technique is stereolithography, by which resin polymer-based materials are made using ultraviolet (UV) radiation. ${ }^{7}$ In fused deposition modeling technique, computer-aided design/computer-aided manufacturing models are made using plastic polycarbonate which is laid in a layered fashion from top to bottom. ${ }^{8}$ In digital light processing technique which is similar to stereolithography, in contrast to UV radiation visible light is used to cure the resin. ${ }^{9}$ Three-dimensional plotting is a recent technology where soft tissue materials like hydrogels (gelatin etc) are used.

The recent trends indicate that viable biomaterials like living cells, cartilage, bone, blood vessels, and muscle tissue can be regenerated. However, every technique has its limitations. In general, the limitations include:

- Nonavailability of biomaterials to achieve macro, micro, and nanostructures especially in the internal architecture

- Prohibitive cost

- High processing temperatures

- Recreating matrix complexity of living tissues even though living cells are successfully employed

- Technical issues involved in laser fabrication. ${ }^{10}$

In this newly emerging field of surgical reconstruction, there is a need to improve the existing 3D printing techniques, particularly in the parameters of high resolution, microstrength, nanoarchitecture, and biocompatibility of materials. The future applications depend on the success in achieving these factors.

\section{REFERENCES}

1. Zaharia C, Gabor AG, Gavrilovici A, Stan AT, Idorasi L, Sinescu C, Negrutiu ML. Digital dentistry-3D printing applications. J Interdiscipl Med 2017 Mar;2(1):50-53. 
2. The history of 3D printing: $3 \mathrm{D}$ printing technologies from the 80s to today. Available from: https://www.sculpteo.com/ blog 2016/12/14/the-history of-3d-printing-3d-printingtechnologies-from-the-80s-to-today/.

3. Wu J, Li Y, Zhang Y. Use of intraoral scanning and 3-dimensional printing in the fabrication of a removable partial denture for a patient with limited mouth opening. J Am Dent Assoc 2017 May;148(5):338-341.

4. Lal K, White GS, Morea DN, Wright RF. Use of stereolithographic templates for surgical and prosthodontic implant planning and placement. Part I. The concept. J Prosthodont 2006 Jan-Feb;15(1):51-58.

5. Heo EY, Ko NR, Bae MS, Lee SJ, Choi BJ, Kim JH, Kim HK, Park SA, Kwon IK. Novel 3D printed alginate-BFP1 hybrid scaffolds for enhanced bone regeneration. J Ind Eng Chem 2017 Jan;45:61-67.

6. Xu F, Wong YS, Loh TH. Toward generic models for comparative evaluation and process selection in rapid prototyping and manufacturing. J Manuf Syst 2000;19(5):283-296.

7. Jacob GS. Three-dimensional printing of dentures using fused deposition modeling. Inside Dent Technol 2013 Jul-Aug;4(8).

8. Dawood A, Marti Marti B, Sauret-Jackson V, Darwood A. 3D printing in dentistry. Br Dent J 2015 Dec;219(11):521-529.

9. Masri, R.; Driscoll, CF. Clinical applications of digital dental technology. London: Wiley; 2015.

10. Chia HN, Wu BM. Recent advances in 3D printing of biomaterials. J Biol Eng 2015 Mar;9:4. 